\title{
Specifics of Basic Biomotor Components for Rhythmic Gymnastics
}

\author{
Endang Murti Sulistyowati ${ }^{1, *}$ Wawan Sundawan Suherman ${ }^{2,}$ Endang Rini Sukamti ${ }^{2}$ \\ Muhammad Imam Rahmatullah ${ }^{3}$, Dinan Mitsalina ${ }^{4}$ \\ ${ }^{1}$ Doctor Program in Sport Science Universitas Negeri Yogyakarta, Yogyakarta, Indonesia \\ ${ }^{2}$ Faculty of Sport Sciece Universitas Negeri Yogyakarta, Yogyakarta, Indonesia \\ ${ }^{3}$ Faculty of teacher training and education Universitas Riau, Riau, Indonesia \\ ${ }^{4}$ Faculty of Sport Science Universitas Negeri Jakarta Jakarta,Indonesia \\ *Corresponding author. Email: endangmurti.2020@student.uny.ac.id
}

\begin{abstract}
Gymnasts' physical fitness is very necessary in rhythmic gymnastics, plus during a pandemic like today, children are more dominant in holding gadgets than doing physical activities for their fitness. The problem in this study is based on observations and surveys conducted in DIY where the lack of children in participating in rhythmic gymnastics and not being properly socialized. The tests that will be carried out by researchers are the basic components of biomotor for girls aged 7-9 years. This study aims to develop special biomotor components for rhythmic gymnastics so that coaches and elementary school sports teachers can find out in choosing gifted and potential children in this gymnastics so that they can be processed towards peak performance. The method chosen is a preliminary study using early childhood subjects. The test instruments used in this biomotor component are balance, flexibility, agility and strength. These components are supporting the basic biomotor components in rhythmic gymnastics so that every gymnast must have mastered the basic components.
\end{abstract}

Keywords: Biomotor, Gymnastics, Rhythmic Gymnastics, Child Growth and Development, Physical Development

\section{INTRODUCTION}

Gymnastics is a sport that can help optimize children's growth and development and as a foundation for other sports, such as effective and efficient movement control. The world gymnastics organization (FIG) consists of 6 categories of gymnastics, namely Artistic Gymnastics, Rhythmic Gymnastics, Aerobic Sports Gymnastics, Trampoline Gymnastics and General Gymnastics [1]. Rhythmic gymnastics according to research requires a lot of physical exercise and concentration to train mentally. This is in line with the opinion written by [2] that the development of gymnasts requires practice and certain theoretical knowledge. This particular exercise and knowledge is because according to the gymnast's internal load it is influenced by the abilities and skills of the body being carried out [3] Rhythmic gymnastics has been obtained since elementary school and is always given in sports lessons. This helps the trainer in training the dynamics of rhythmic gymnastics, the child's ability to learn to learn various movements in addition to being able to explore children's motor skills can also support components in rhythmic gymnastics. The trainer's efforts in making motor skills training programs can help in the perfection of motor skills.

Rhythmic gymnastics is gymnastics that has a relatively wide range of motion development compared to instrument gymnastics and artistic gymnastics. This gymnastics starts from early childhood, especially for girls and at an early age is a golden period in growth where children have a high ability and willingness to learn, the age of children to practice starts from the age of 6-8 years, specialization ages 9-10 years and peak performance 14-18 years. At an early age, children still like to run, jump, chase each other, which children do not realize are already exploring their biomotor abilities [4]. This affects the physical condition of the child, especially in the biomotor component. Rhythmic 
Gymnastics is gymnastics that has three basic elements of movement using music and combined with the equipment used. A series of rhythmic gymnastics can be done with tools. Rhythmic gymnastics places more emphasis on music, flexibility, and continuous and regular practice. The music used is one of the important elements because with music athletes will be more enthusiastic in participating in training so that a fun training process is formed. The mattress used is $13 \mathrm{~m} \mathrm{x}$ $13 \mathrm{~m}$ and for a maximum duration of 1.30 minutes. The tools used are quite easy to obtain so that it is possible to practice with many participants. Elements of sports rhythmic gymnastics have been determined by Code Of Point 2017 [5]. The mattress used is $13 \mathrm{~m} \mathrm{x} 13 \mathrm{~m}$ and for a maximum duration of 1.30 minutes. The tools used are quite easy to obtain so that it is possible to practice with many participants. Elements of sports rhythmic gymnastics have been determined by Code Of Point 2017 [5]. The mattress used is $13 \mathrm{~m} \times 13 \mathrm{~m}$ and for a maximum duration of 1.30 minutes. The tools used are quite easy to obtain so that it is possible to practice with many participants. Elements of sports rhythmic gymnastics have been determined by Code Of Point 2017 [5].

The achievements will be supported by several physical factors, techniques, tactics, strategies, coaches, athletes, facilities and infrastructure. The training process is inseparable from physical exercise so that the athlete's physical condition improves so that it can help maximize peak performance. At the peak achievement stage it requires an orderly, measurable and structured system through a short, medium, and long term process [6]. Rhythmic gymnastics does not only involve musical instruments, ballet movements and elemental movements but requires continuous movement with dynamic motor movements, of course according to the stages of age [7].

Biomotor is the ability of humans to move as seen from breathing, bones, joints, energy, and the nervous system so that if energy can be fulfilled and stored in the muscles, a movement will appear. All systems in the body have a very important role in converting energy into muscles. This also occurs in the biomotor component because it is a physical condition needed by athletes. The most appropriate way to choose children who have good biomotor components is to use talent scouting [8]. Biomotor is the movement of the human body that is influenced by organ systems such as neuromuscular, respiratory, blood circulation, energy, bones, joints so that these components are the overall physical condition of sports. All sports activities in the majority contain components of strength, speed, endurance and complex movements that require extensive joint motion The dominant biomotor elements in rhythmic sportsmanship are flexibility, strength, agility, speed, endurance, coordination [9]. A person's biomotor is very influential when doing various physical activities [10].
In addition, biomotor abilities are acquired in a programmed development process. This is in accordance with research conducted by Manggau \& Usman. [11] before being programmed and trained in rhythmic gymnastics, children already have their own movement skills. According to [12] that by conducting various biomotor tests is an effective way to determine endurance, flexibility, strength, balance in early childhood. agility, speed, endurance, coordination.

In the formation of bimotor influenced by physical quality. These physical qualities are divided into two, namely nature and nurture. Nature is a natural or innate physical quality, while nurture is a physical quality that goes through a developmental process that is formed based on a series of training programs provided by the trainer. For rhythmic gymnastics it also requires both so that an athlete can develop the physical quality of his biomotor by following a regular exercise program. The coach must understand the basic physical qualities of the biomotor involved in gymnastics so that the goals obtained become clearer.[13]

The relationship between biomotor components is needed in rhythmic gymnastics but in the strength component, agility is needed a little [14]. From various studies, no research has been found on the biomotor component for rhythmic gymnastics, so the researchers researched the biomotor component for rhythmic gymnastics for early childhood.

\section{METHOD}

The type of research used is a preliminary study. This research model aims to develop, test. This preliminary study was carried out in March 2021 in the DIY region. Researchers observed and surveyed in public and private elementary schools, each two schools as well as gymnastic clubs in each district and municipality, then recorded and added supporting literature on rhythmic gymnastics. From these observations, there were 20 sports teachers in elementary schools and 5 trainers for rhythmic gymnastics club in Yogyakarta.

\section{RESULT AND DISCUSSION}

The results of observations and surveys obtained in DIY are some of the basic components involved, this is synchronized with previous research data that the basic components involved in rhythmic gymnastics are flexibility, agility, speed, balance, strength. Flexibility includes sit and reach and bridge which will be shown in Figures 1 and 2. Agility will be shown in Figure 3. Balance will be shown in Figure 4. Strength will be shown in Figures 5 and 6. 


\subsection{Flexibility}

[13] Flexibility is the most dominant factor in rhythmic gymnastics so that flexibility is very influential on the biomotor component. Flexibility is the area of joint motion, which means that the wider and larger the joint motion, the better the flexibility. In rhythmic gymnastics the most important is the flexibility of bending the body forward and backward (siat and reach and bridge).
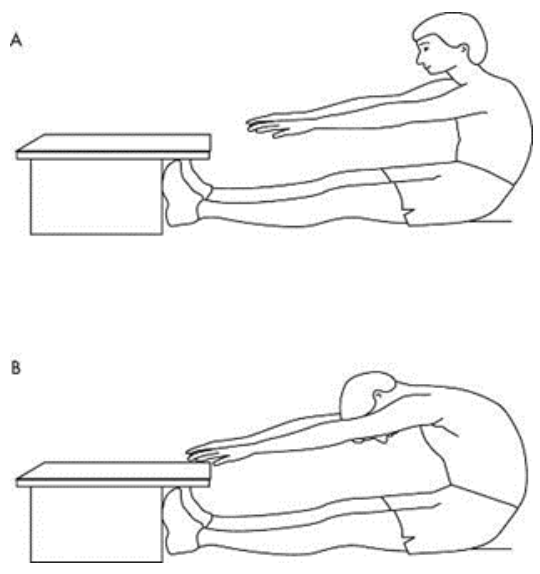

Figure 1. Sit and reach
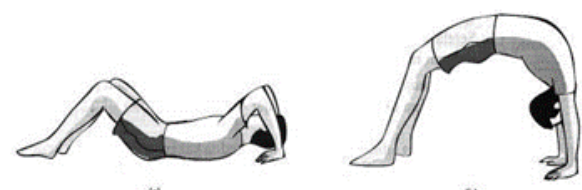

Figure 2. Bridge

\subsection{Agility}

Agility is a person's ability to change direction and position quickly while doing other movements simultaneously. In the branch of rhythmic gymnastics, agility is an important component because athletes must be agile, skilled in performing various movements with or without tools accompanied by music and also change direction quickly and consistently in rhythm. [13]

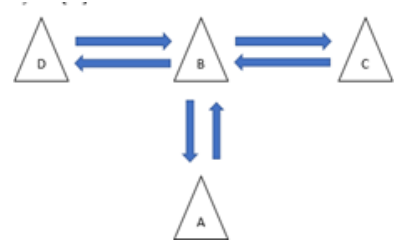

Figure 3. T-test

\subsection{Balance}

Balance is the ability to hold on to one leg or stay in the air stably without rocking or when performing static or dynamic balance movements. Balance affects gymnastic movements, balancing body position with movement and tools. Basic static balance can be trained for early childhood in this sport.[13]

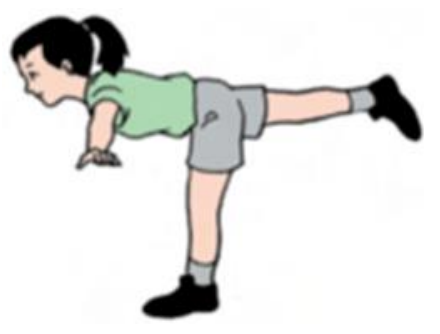

Figure 4. Balance

\subsection{Strength}

Strength is one of the basic components in rhythmic gymnastics. The goal is to train to increase muscle power so that the muscles are able to withstand the load in training. So that strength is the basic biomotor in shaping athletes.[15]. In rhythmic gymnastics, the strength that is often used is the strength of the abdominal muscles which can be used to do locks and the strength of the leg muscles where the athlete must jump and rotate with the axis of one leg, and so on.

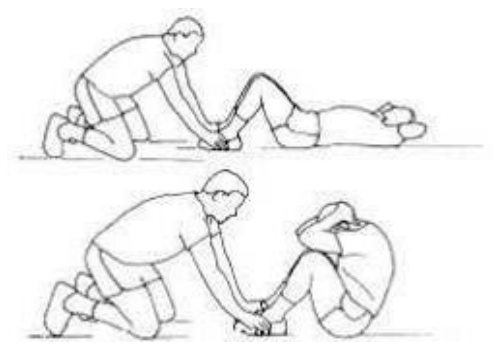

Figure 5. Sit Up

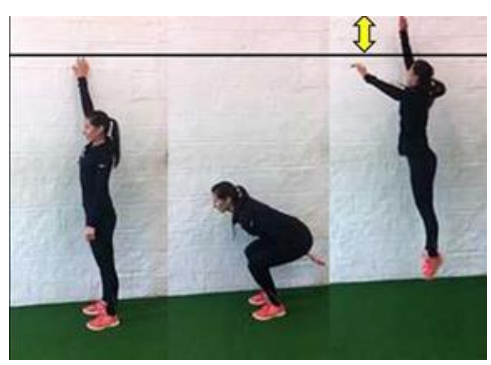

Figure 6. Vertical Jump

\section{CONCLUSION}

Achievement in gymnastics athletes can be supported through physical, technical, tactical, strategy, coach, athlete themselves, and supporting facilities. Achievements in improving the physical quality of biomotors with the aim of conditioning the body's stamina in routine practice to achieve peak performance, agility, balance and strength. Seuntil early childhood 
who will enter the gymnastics branch can explore, develop, and improve these basic components

\section{ACKNOWLEDGMENTS}

The author would like to thank the lectures who have guided, friends who have helped, teachers trainers, and students who have participated in this research.

\section{REFERENCES}

[1] A Mahendra. Gymnastics Learning Approach Dominant Movement Pattern for Junior High School Students. 2001. Director General of Sports, Jakarta

[2] Arce,MB,Rial,BM Determinants of competitive performance inrhythmic gymnastics. A review. Proseding from spain,2013, , pp711-727

[3] M,A,F Villarino. A,H Sanchez, ,E,S. Palmeiro, ,M,B. Arce Performance indicators in individual rhythmic gymnastics:correlation in competition in Journal of Human Sport \& Exercise. 2018. vol 13, pp. 487-493

[4] Ria Lumintuarso, Pemanduan bakat multilateral.2013.UNY. handbook

[5] Federation Internationale de Gymnastics.. 20172020code of point rhythmic gymnastics.2017.United States:FIG. handbook

[6] Bompa, Theory of periodization and training methodology.fifth edition. 2009.handbook

[7] SM. Dobrijevic,. L Moskovljevic., Marcovic, M., , M. Dabovic Effects of propioceptive training on explosive strength, agility, and coordination of young rhythmic gymnasts.Physical culture journal.2018. vol. 72, pp. 71-79.

[8] DL. Mann,, , N. Dehghansai,, J. Baker Searching for the elusive gift: advances in talent identification in sport.Journal of medicine.2017. vol 16, pp. 128-133

[9] Bompa Theory and Methodology of Training. (third edition). 1994 Dubuque, Iowa:Kendal/ Hunt Publishing Company.handbook

[10] A.kumar sigh,M elayanara. Determination of somatotype in 8-to 14 year males in the districts of chandauli and mirzapur uttar Pradesh india.2017 vol 2. Pp 679-689

[11] A.Manggau, A. Usman. Development the Gross Motor Skills of Children by Simultaneously Training Them with Rhythmic Gymnastics. Vol.6.publihed
[12] E, R Sukamti., R. Budiarti, , R. Nurfadilah. Effect of physical conditioning on student basic skills gymnastics Education Horizon. 2020. vol 39, pp. 207-216.

[13] Ch Fajar Sriwahyuniati. Physical biomotor components. Achievement sports journal. 2009. Vol 5. No. PP 259-277

[14] Corbin, CB, Welk, GJ, \& Corbin, WR The concept of fitness and wellness. 2009.Toronto: McGraw Hill. Company

[15] Sukadiyanto. Physical exercise theory and methodology petennis. 2002. 